\title{
Ammonium Nitrogen Tolerant Chlorella Strain Screening and Its Damaging Effects on Photosynthesis
}

\section{OPEN ACCESS}

Edited by:

Weiwen Zhang

Tianjin University, China

Reviewed by:

Giorgos Markou,

Hellenic Agricultural Organization -

ELGO, Greece

Weimin Ma

Shanghai Normal University, China

Harvey J. M. Hou,

Alabama State University,

United States

*Correspondence:

Qiang Wang

wangqiang@ihb.ac.cn.

Specialty section:

This article was submitted to

Microbiotechnology, Ecotoxicology

and Bioremediation,

a section of the journal

Frontiers in Microbiology

Received: 08 October 2018

Accepted: 14 December 2018

Published: 07 January 2019

Citation:

Wang J, Zhou W, Chen H, Zhan J, He C and Wang Q (2019) Ammonium

Nitrogen Tolerant Chlorella Strain

Screening and Its Damaging Effects

on Photosynthesis.

Front. Microbiol. 9:3250.

doi: 10.3389/fmicb.2018.03250

\author{
Jie Wang ${ }^{1,2}$, Wei Zhou ${ }^{1,2}$, Hui Chen ${ }^{1,3}$, Jiao Zhan ${ }^{1}$, Chenliu He ${ }^{1}$ and Qiang Wang ${ }^{1,2 *}$ \\ ${ }^{1}$ Key Laboratory of Algal Biology, Institute of Hydrobiology, Chinese Academy of Sciences, Wuhan, China, ${ }^{2}$ University of the \\ Chinese Academy of Sciences, Beijing, China, ${ }^{3}$ Donghu Experimental Station of Lake Ecosystems, State Key Laboratory of \\ Freshwater Ecology and Biotechnology of China, Institute of Hydrobiology, Chinese Academy of Sciences, Wuhan, China
}

Nitrogen is an essential nutrient element. Ammonium nitrogen, one of the most common nitrogen sources, is found in various habitats, especially wastewater. However, excessive amounts of ammonium nitrogen can be toxic to phytoplankton, higher plants, fish, and other animals, and microorganisms. In this study, we explored the tolerance of green algae to ammonium nitrogen using 10 Chlorella strains. High concentrations of ammonium nitrogen directly inhibited the growth of Chlorella, but the degree of inhibition varied by strain. With the $\mathrm{EC}_{50}$ of 1.6 and $0.4 \mathrm{~g} \mathrm{~L}^{-1}$, FACHB-1563 and FACHB-1216, respectively had the highest and lowest tolerance to ammonium nitrogen among all strains tested, suggesting that FACHB-1563 could potentially be used to remove excess ammonium nitrogen from wastewater in bioremediation efforts. Two strains with the highest and lowest tolerance to ammonium nitrogen were selected to further explore the inhibitory effect of ammonium nitrogen on Chlorella. Analysis of chlorophyll fluorescence, oxygen evolution, and photosynthesis proteins via immunoblot showed that photosystem II (PSII) had been damaged when exposed to high levels of ammonium nitrogen, with the oxygen-evolving complex as the primary site, and electron transport from $Q_{A}^{-}$to $Q_{B}$ was subsequently inhibited by this treatment. A working model of ammonium nitrogen competition between $\mathrm{N}$ assimilation and PSIl damage is proposed to elucidate that the assimilation rate of ammonium nitrogen by algae strains determines the tolerance of cells to ammonium nitrogen toxicity.

\section{Keywords: ammonium nitrogen, biological remediation, Chlorella, oxygen-evolving complex, photosynthesis}

\section{INTRODUCTION}

Nitrogen is one of the most important elements on Earth. Many different forms of nitrogen exist in the biosphere. Molecular nitrogen $\left(\mathrm{N}_{2}\right)$ is the main form, accounting for $\sim 78 \%$ of the Earth's atmosphere. Free nitrogen molecules in the atmosphere can be converted into combined nitrogen via atmospheric, industrial, and biological nitrogen fixation (Lanyon, 1995; Nishibayashi et al., 2004; Olivares et al., 2013). Combined nitrogen, primarily ammonium nitrogen and nitrate nitrogen, subsequently become the objects of intense competition among plants and microorganisms (Costa et al., 2001; Alves et al., 2016). Ammonium nitrogen can be directly assimilated into amino acids via the enzymes glutamine synthetase (GS) and glutamate synthase (GOGAT) (Wu et al., 2016), whereas nitrate nitrogen must first be reduced to nitrite nitrogen in 
the cytosol, after which it is immediately reduced to ammonium nitrogen in chloroplasts or plastids (Monier et al., 2015). Nitrate reductase and nitrite reductase catalyze these reduction reactions, respectively (Daniel-Vedele et al., 1998; Fernandez and Galvan, 2007). An additional reduction process, nitrate nitrogen assimilation, requires more energy, and ammonium nitrogen is considered to be more efficient than nitrate nitrogen in terms of energy utilization (Ruan and Giordano, 2017). However, ammonium nitrogen can be toxic to many organisms, particularly plants, and oxygenic photosynthetic microorganisms (Drath et al., 2008; Markou et al., 2014).

Ammonium nitrogen, which usually refers to nitrogen in the form of free ammoniacal nitrogen $\left(\mathrm{NH}_{3}\right)$ and ammonium ions $\left(\mathrm{NH}_{4}^{+}\right)$, is present in natural waters, with higher levels found in wastewater, such as domestic wastewater (Cruz et al., 2018), industrial waste (Huang et al., 2009), and aquaculture waste (Lu et al., 2015). $\mathrm{NH}_{3}$ and $\mathrm{NH}_{4}^{+}$can be present in a solution simultaneously. The $\mathrm{pKa}$ (ion dissociation constant) of the $\mathrm{NH}_{4}^{+} / \mathrm{NH}_{3}$ buffer system is about 9.25 at $25^{\circ} \mathrm{C}$, meaning that at $\mathrm{pH}<9.25$, the dominant form is $\mathrm{NH}_{4}^{+}$, while at $\mathrm{pH}>9.25$, the dominant form is $\mathrm{NH}_{3}$. The content of $\mathrm{NH}_{3}$ in a specific concentration of ammonium nitrogen can be calculated using the equation $\mathrm{NH}_{3}(\%)=100 /(1+10 *(\mathrm{pKa}-\mathrm{pH})$ ) (Körner et al., 2001), which is closely related to the $\mathrm{pH}$ of the medium and increases with increasing $\mathrm{pH}$.

Several mechanisms have been proposed to explain the toxic effects of ammonium nitrogen: the ammonium nitrogen assimilation process destroys the carbon and nitrogen balance in plants (Kronzucker et al., 1998); ammonium nitrogen transport disrupts intracellular $\mathrm{pH}$ balance (Pearson and Stewart, 1993); the long-term use of $\mathrm{NH}_{4}^{+}$leads to the loss of cations such as $\mathrm{Mg}^{2+}, \mathrm{Ca}^{2+}$, and $\mathrm{K}^{+}$in the cell, leading to a nutrient imbalance (Li et al., 2012); the ineffective transmembrane cycling of $\mathrm{NH}_{3}$ leads to energy loss (Speer and Kaiser, 1994); and $\mathrm{NH}_{3}$ affects the oxygen-evolving complex (OEC) by displacing a water ligand to the outer Mn cluster of the OEC (Dai et al., 2008; Tsuno et al., 2011). However, to what extent phytoplankton can tolerate and/or efficiently assimilate ammonium nitrogen is unknown, and the primary target of ammonium nitrogen damage in the photosynthetic machinery remains to be identified.

The green alga Chlorella is highly resistant to ammonium nitrogen. Chlorella can use ammonium nitrogen for growth, making it possible to use this alga for bioremediation to remove ammonium nitrogen (Tam and Wong, 1996). In addition, due to the abundant proteins and biolipids found in Chlorella, it is sometimes used as a health product or biological bait, as well as for biodiesel production (Zhang et al., 2014).

In this study, we screened 10 Chlorella strains for tolerance to ammonium nitrogen, analyzed the underlying tolerance mechanism, and proposed a working model based on the competition between $\mathrm{N}$ assimilation and PSII damage by ammonium nitrogen in the chloroplast.

\section{MATERIALS AND METHODS}

\section{Algae Strains}

Chlorella strains Chlorella sorokiniana W1, Chlorella sp. W2, C. sorokiniana W3, C. sorokiniana W4, C. sorokiniana W5, and C. sorokiniana W6 were collected from the wild and preserved in the China Center for Type Culture Collection (Chen et al., 2017). Strains FACHB-1, FACHB-1216, FACHB-1535, and FACHB-1563 were obtained from the Freshwater Algae Culture Collection of the Institute of Hydrobiology, Chinese Academy of Sciences (Li et al., 2016).

\section{Growth Conditions and Ammonium Nitrogen Treatment}

The N-sufficient medium used for the control group was fullstrength BG11 medium, whereas $\mathrm{N}$-deficient BG11 medium supplied with high concentration $\mathrm{NH}_{4} \mathrm{Cl}\left(\mathrm{HC}, 0.5 \mathrm{~g} \mathrm{~L}^{-1}\right)$ or low concentration $\mathrm{NH}_{4} \mathrm{Cl}$ (LC, $0.05 \mathrm{~g} \mathrm{~L}^{-1}$ ) was used for the treatment groups. The initial $\mathrm{pH}$ of the medium for both groups was adjusted to $\sim 7.5$ by adding $\mathrm{NaOH}$ or $\mathrm{HCl}$; at this $\mathrm{pH}, \mathrm{NH}_{4}^{+}$ is the dominant form of ammonium nitrogen, whereas $\mathrm{NH}_{3}$ comprises only $\sim 2.5 \%$ of the total. Chlorella cells at the midlogarithmic phase $\left(\mathrm{OD}_{700} \sim 0.8\right)$ were harvested by centrifugation at $3,000 \mathrm{~g}$ for $3 \mathrm{~min}$ at $25^{\circ} \mathrm{C}$. The pellet was washed with $\mathrm{N}$ free BG11 medium and re-suspended to $\mathrm{OD}_{700} 0.1$ for both the control and treatment groups. All Chlorella strains were cultured in $100 \mathrm{~mL}$ Erlenmeyer flasks containing $50 \mathrm{~mL}$ of culture medium at $25^{\circ} \mathrm{C}$ with continuous illumination at $70 \mu \mathrm{mol} \mathrm{m}{ }^{-2} \mathrm{~s}^{-1}$ and continuous rocking on a shaker at $150 \mathrm{rpm}$. The $\mathrm{OD}_{700}$ value was measured daily with a spectrophotometer, and the data were used to track cell growth. The $\mathrm{pH}$ and ammonium nitrogen content of the supernatant were also measured daily. The $\mathrm{pH}$ was measured with a glass electrode, and the ammonium nitrogen content was measured as described previously (Tam and Wong, 1996).

\section{$\mathrm{NH}_{3}$ Sensitivity and Adaptation Analysis of Various Chlorella Strains}

Chlorella strains grown in N-deficient BG11 medium supplied with different concentrations of $\mathrm{NH}_{4} \mathrm{Cl}(0.1,0.5,1,1.5,2,2.5$, 3 , and $4 \mathrm{~g} \mathrm{~L}^{-1}$ ) served as the treatment groups, and cells grown in full-strength BG11 medium served as the control group. All Chlorella strains were grown under continuous illumination at $70 \mu \mathrm{mol} \mathrm{m} \mathrm{m}^{-2} \mathrm{~s}^{-1}$ (white light) with the same initial $\mathrm{OD}_{700}$ of 0.4. To increase the proportion of $\mathrm{NH}_{3}$ in ammonium nitrogen, the initial $\mathrm{pH}$ level of the media for both the control and treatment groups was adjusted to 9.25 by adding $\mathrm{NaOH}$ or $\mathrm{HCl}$, at which point the content of $\mathrm{NH}_{3}$ theoretically occupies $\sim 56 \%$ of the total. The Fv/Fm of each sample was measured after $2 \mathrm{~h}$ of treatment. The $50 \%$ effective concentration $\left(\mathrm{EC}_{50}\right)$, corresponding to the $\mathrm{NH}_{4} \mathrm{Cl}$ concentration at which the Fv/Fm is half that of the control, was used to reflect the relative level of ammonium nitrogen tolerance (Dai et al., 2014). The EC 50 was calculated by Probit analysis in the SPSS-19 (Hoekstra, 1991).

The Chlorella strains with the highest and lowest tolerance to ammonium nitrogen (FACHB-1563 and FACHB-1216) were chosen among the 10 Chlorella strains. The mean value of the $\mathrm{EC}_{50}\left(1 \mathrm{~g} \mathrm{~L}^{-1}\right)$ of the two selected Chlorella strains was used as the $\mathrm{NH}_{4} \mathrm{Cl}$ treatment concentration in subsequent analyses. The growth conditions were the same as those used for screening. 


\section{GOGAT and GS Activity Measurement}

GS and GOGAT activity were measured according to MartinFigueroa et al. (2000) using GS and GOGAT test kits purchased from the Beijing Solarbio Science \& Technology Co., Ltd., China.

\section{Chlorophyll Fluorescence Measurements}

Quantum Yield (QY), chlorophyll fluorescence induction kinetics (OJIP), and Non-Photochemical Quenching (NPQ) were measured using an AquaPen-C AP-C 100 fluorometer. Red light was used as the measuring light, the measuring flash pulse was set to $0.009 \mu \mathrm{mol} \mathrm{m} \mathrm{m}^{-2} \mathrm{~s}^{-1}$, the saturating pulse was 2,100 $\mu \mathrm{mol} \mathrm{m} \mathrm{m}^{-2} \mathrm{~s}^{-1}$, and the actinic light (A-pulse) level was 400 $\mu \mathrm{mol} \mathrm{m} \mathrm{m}^{-2} \mathrm{~s}^{-1}$ (Zhang et al., 2016). Chlorophyll fluorescence parameters Fv/Fm, Y(II), and Y(NO) and JIP-test parameters Qp and $\mathrm{Mo}, \Psi_{\mathrm{o}}, \varphi \mathrm{Eo}$, and $\mathrm{Wk}$ were used in this study, which were calculated according to the following equations:

$$
\begin{aligned}
\mathrm{Fv} / \mathrm{Fm} & =(\mathrm{Fm}-\mathrm{Fo}) / \mathrm{Fm} \\
\mathrm{Y}(\mathrm{II}) & =(\mathrm{Fm}-\mathrm{F}) / \mathrm{Fm} \\
\mathrm{Y}(\mathrm{NO}) & =\mathrm{F} / \mathrm{Fm} \\
\mathrm{Qp} & =(\mathrm{Fm}-\mathrm{F}) /(\mathrm{Fm}-\mathrm{Fo}) \\
\varphi \mathrm{Eo} & =\left(1-\left(\mathrm{F}_{\mathrm{O}} / \mathrm{F}_{\mathrm{M}}\right)\right) * \Psi_{\mathrm{O}} \\
\mathrm{Wk} & =(\mathrm{Ft}-\mathrm{Fo}) /\left(\mathrm{F}_{\mathrm{J}}-\mathrm{Fo}_{0}\right) \\
\mathrm{Mo} & =4\left(\mathrm{~F}_{300 \mu \mathrm{s}}-\mathrm{Fo}_{\mathrm{O}}\right) /\left(\mathrm{F}_{\mathrm{M}}-\mathrm{Fo}\right) \\
\Psi_{\mathrm{o}} & =\mathrm{ETo} / \mathrm{TRo}=1-\mathrm{V}_{\mathrm{J}}
\end{aligned}
$$

\section{Photosynthetic Oxygen Evolution and Dark Respiration Rates}

Photosynthetic oxygen evolution and dark respiration rates were measured as described by Zhang et al. (2013).

\section{SDS-PAGE and Immunoblot Analysis}

SDS-PAGE and immunoblot analysis of cellular proteins were performed according to Zhang et al. (2016).

\section{Statistical Analysis}

For each result shown, the data are the average of three biological replicates. Data were analyzed using SPSS-19. Significance was determined using a one-way ANOVA at the $P<0.05$ or $P<0.01$ confidence limits.

\section{RESULTS}

\section{Ammonium Nitrogen Directly or Indirectly Inhibits Chlorella Growth}

Analysis of the growth curves of the 10 Chlorella strains under LC conditions revealed no significant differences $(P>0.05)$ compared to the control group cultured in standard BG11 medium for the first 3 days, after which the growth rates began to decrease and some Chlorella strains perished (Figure 1). When cultivated under HC conditions, most Chlorella strains showed similar growth patterns to those cultivated under LC conditions, but the growth of FACHB-1216 was inhibited at the beginning of the treatment. We also measured the ammonium nitrogen content in the growth medium, which exhibited similar tendencies for all 10 Chlorella strains (Figure 2). The ammonium nitrogen content gradually decreased during growth, even approaching 0 on day 3 under LC conditions. By contrast, under HC conditions, only a slight decrease in ammonium nitrogen content $(\sim 10 \%)$ was detected. The residual ammonium nitrogen content was sufficiently high $\left(0.45 \mathrm{~g} \mathrm{~L}^{-1}\right)$ when cell growth under $\mathrm{HC}$ conditions was inhibited during the middle and later stages of growth. These results indicate that the algal growth inhibition or even death observed in the middle and late stages in the HCtreatment group was not due to the consumption of ammonium nitrogen.

The initial $\mathrm{pH}$ value of the culture medium was $\sim 7.5$ for all treatments; at this $\mathrm{pH}, \mathrm{NH}_{4}^{+}$is the dominant form of ammonium nitrogen. During the early stage of growth, the $\mathrm{pH}$ values of all samples in the treatment group were stable. However, these values rapidly decreased to $\sim \mathrm{pH} 3$ on the fourth day of culture and stabilized with increasing culture time (Figure 3), which is consistent with the time of growth inhibition for most Chlorella strains (Figure 1). In acidic environment, many enzymes become inactive (Williams and Colman, 1996) and gross oxygen production was lowered (Ihnken et al., 2014) in Chlorella. Therefore, we speculated that the growth inhibition in the middle and late stages was due to acidification of the medium. However, we detected a significant difference in cell growth in FACHB-1216 between control and HC conditions throughout the experiment, suggesting that ammonium nitrogen can also directly inhibit Chlorella growth.

\section{The Ability to Assimilate Ammonium Nitrogen Determines the Tolerance of Chlorella to Ammonium Nitrogen}

As the amount of free $\mathrm{NH}_{3}$ in a specific concentration of ammonium nitrogen solution is $\mathrm{pH}$ dependent, we increased the initial $\mathrm{pH}$ values of the culture medium to $\mathrm{pH} 9.25$ to increase the content of $\mathrm{NH}_{3}$ and measured the $\mathrm{EC}_{50}$ of the 10 Chlorella strains to further explore the mechanism underlying tolerance to ammonium nitrogen (Table 1). Most Chlorella strains tested were highly tolerant to ammonium nitrogen $\left(\mathrm{EC}_{50}>1 \mathrm{~g} \mathrm{~L}^{-1}\right)$; even the $\mathrm{EC}_{50}$ values of FACHB-1563 and FACHB-1535 were $>1.6 \mathrm{~g}$ $\mathrm{L}^{-1}$. FACHB-1216 showed the lowest tolerance to ammonium nitrogen, with an $\mathrm{EC}_{50}$ of $0.4 \mathrm{~g} \mathrm{~L}^{-1}$. The high sensitivity of FACHB-1216 to ammonium nitrogen might explain why cell growth in this culture was inhibited throughout the cultivation period (Figure 1).

To identify the cause of the differences in ammonium nitrogen tolerance among strains, we selected the Chlorella strains with the highest and lowest tolerance to ammonium nitrogen (FACHB1563 and FACHB-1216). The growth rate significantly differed $(P<0.05)$ between FACHB-1216 and FACHB-1563, whereas $\mathrm{pH}$ values exhibited similar trends (Figure 4), indicating that the tolerance of these lines to ammonium nitrogen indeed differed.

In nitrogen metabolism, ammonium nitrogen are fixed via the glutamate-glutamine cycle, in which ammonium nitrogen combines with glutamate catalyzed by GS to form glutamine, and GOGAT transfers the amide group of glutamine to 2oxoglutarate, yielding two molecules of glutamate, followed 

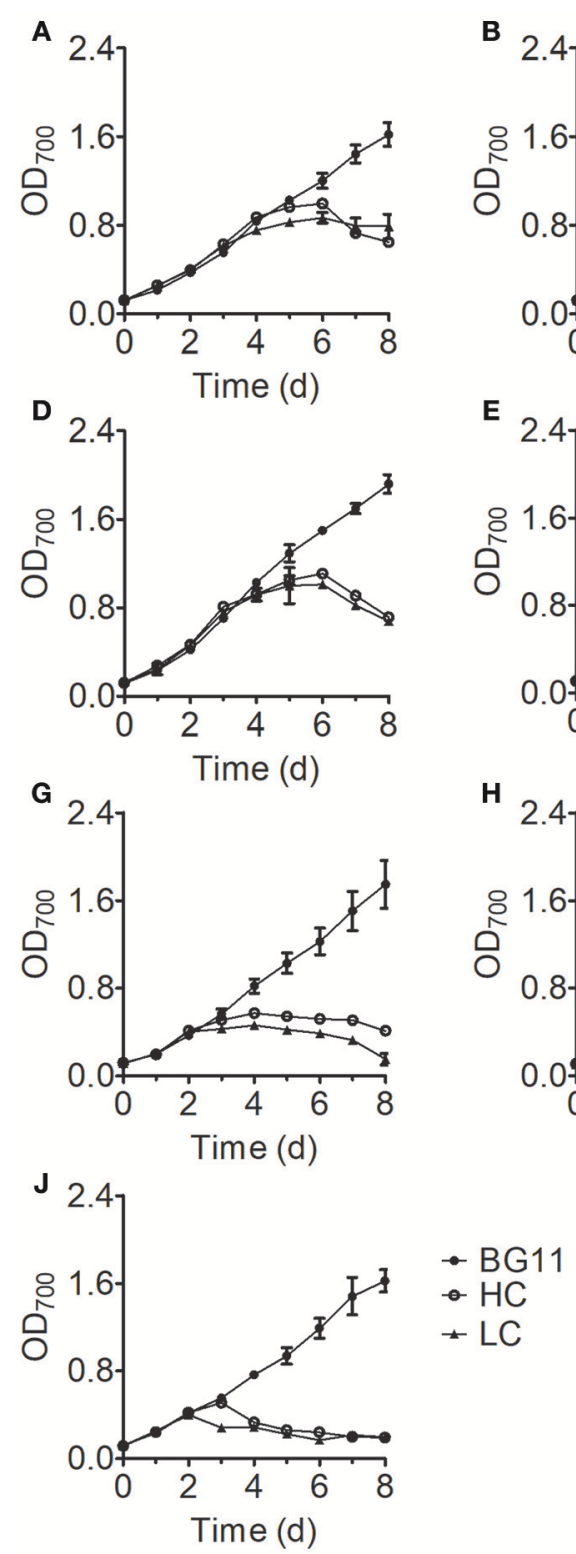
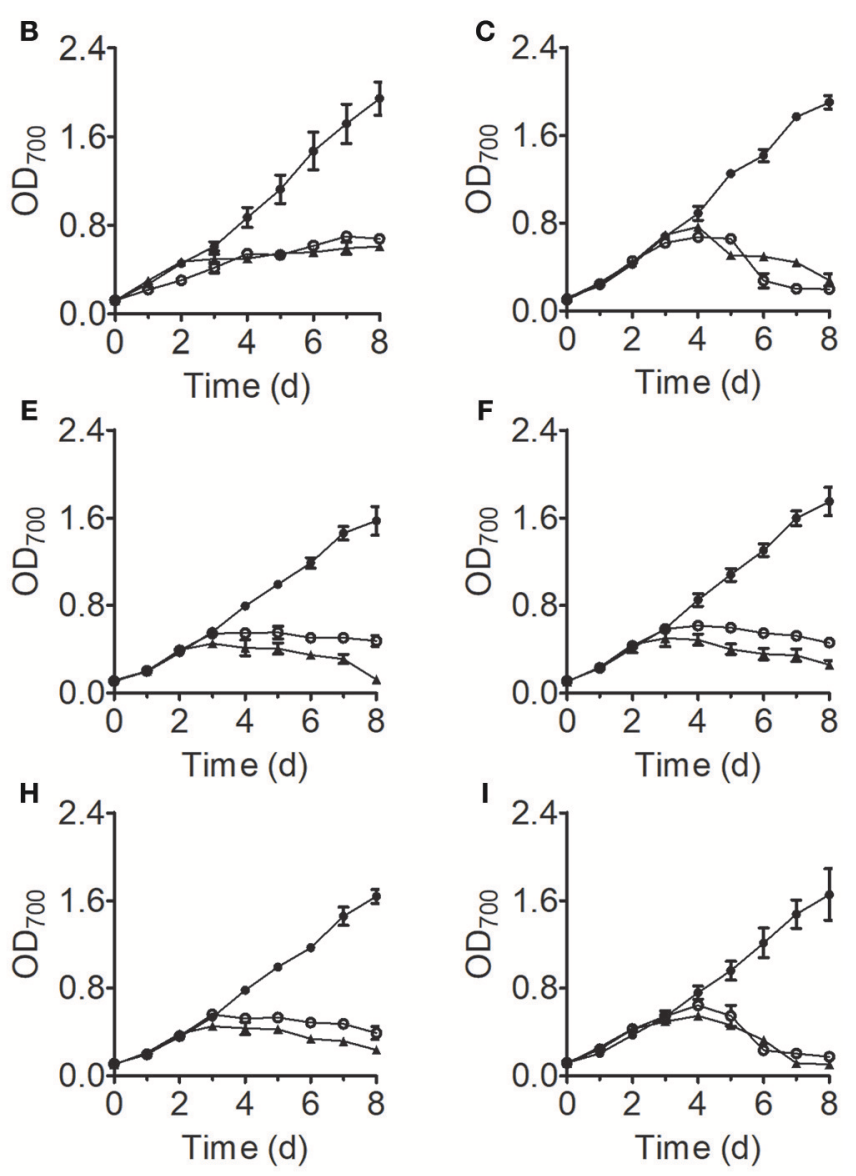

FIGURE 1 | Growth curves of 10 Chlorella strains cultivated in BG11 medium (BG11) and in N-deficient BG11 medium supplemented with $0.5 \mathrm{~g} \mathrm{~L}^{-1} \mathrm{NH} \mathrm{Cl}_{4} \mathrm{Cl}$ ( $)$ or $0.05 \mathrm{~g} \mathrm{~L}^{-1} \mathrm{NH}_{4} \mathrm{Cl}$ (LC). (A-J) Represent Chlorella strain FACHB-1, FACHB-1216, FACHB-1535, FACHB-1563, W1, W2, W3, W4, W5, and W6, respectively. For all figures, the data points represent the means of three replicate experiments for each independent culture, with the SD of the means.

by re-distribution of the assimilated nitrogen into other key molecules, e.g., amino acids and nucleic acids (Chen et al., 2017). To further investigate the contribution of nitrogen assimilation to the tolerance of Chlorella to ammonium nitrogen, we measured the activity of the two key enzymes that catalyze ammonium nitrogen assimilation, GOGAT and GS (Figure 5). After $5 \mathrm{~h}$ of $\mathrm{NH}_{4} \mathrm{Cl}$ treatment, GOGAT activity in both FACHB-1216 and FACHB-1563 decreased slightly. Notably, during this period, GS activity in FACHB-1216 decreased $(P<0.05)$, but GS activity in FACHB-1563 increased significantly $(P<0.01)$, suggesting that the increase in GS activity in this strain promoted ammonium nitrogen assimilation and alleviated the toxicity of this compound to the cell, thereby leading to better ammonium nitrogen tolerance in FACHB-1563 compared to FACHB-1216.

Thus, for the strain with high sensitivity to ammonium nitrogen, ammonium nitrogen had a direct toxic effect on the algae. For the strain with high tolerance to ammonium nitrogen, cell growth was not affected at the initial stages of growth. However, the culture medium gradually became acidified with the constant assimilation of $\mathrm{NH}_{4}^{+}$, which indirectly led to growth inhibition, and even death of the algae. Therefore, the ability of Chlorella to assimilate ammonium nitrogen determines its tolerance to this compound. 

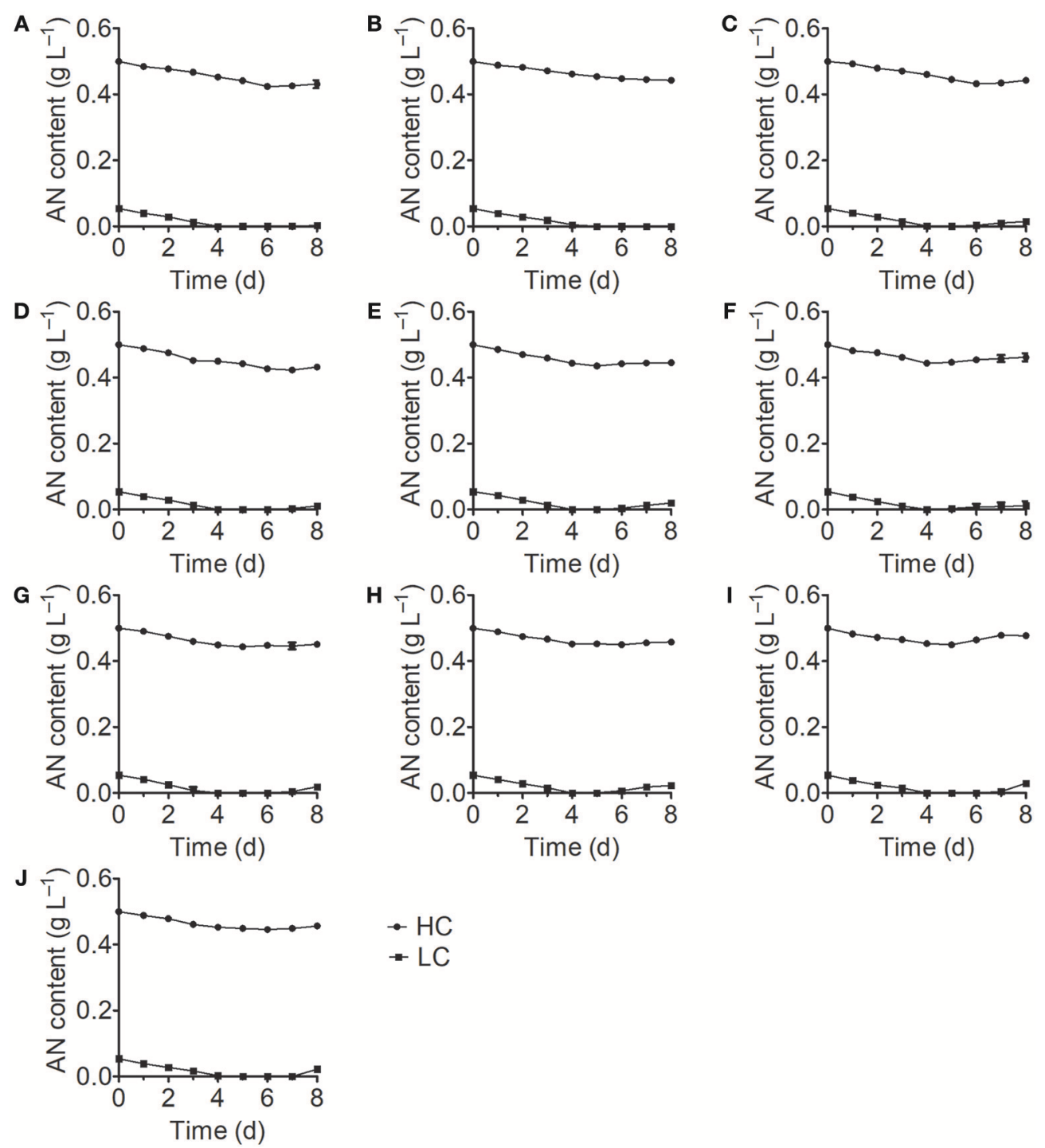

FIGURE 2 | Ammonium nitrogen (AN) content of 10 Chlorella strains cultivated in HC (circles) and LC (squares) medium. (A-J) Represent Chlorella strain FACHB-1, FACHB-1216, FACHB-1535, FACHB-1563, W1, W2, W3, W4, W5, and W6, respectively.

\section{High Levels of Ammonium Nitrogen Damage PSII in Chlorella}

To measure the effect of ammonium nitrogen on photosynthesis, we analyzed the oxygen evolution and respiration rates of FACHB-1216 and FACHB-1563 (Figure 6). Compared to the control, the oxygen evolution and respiration rates in FACHB1563 were not markedly different $(P>0.05)$, whereas these values were markedly different in FACHB-1216 $(P<0.05)$. Oxygen evolution dropped to 0 and the respiration rate declined $\sim 50 \%$ after $5 \mathrm{~h}$ of $\mathrm{HC}$ treatment in FACHB-1216. The results indicated that ammonium nitrogen has adverse effects on the photosynthesis, and the degrees were strain dependent.

Chlorophyll fluorescence measurement, a simple, quick, and reliable method to study the changes of photosynthesis, has long been considered one of the most sensitive and noninvasive tools to investigate stress responses of photosynthesis under unfavorable conditions (Krause, 1991). To gain more insight into the effect of ammonium nitrogen on photosynthesis, various chlorophyll fluorescence parameters were investigated. The chlorophyll fluorescence parameters of maximum photosynthetic efficiency (Fv/Fm), practical photosynthetic efficiency [Y(II)], non-regulated energy dissipation [Y(NO)], and photochemical quenching (Qp) values of FACHB-1216 and FACHB-1563 were measured to further explored the effect of ammonium nitrogen on photosynthesis in this study. The decreased values of Fv/Fm and Y(II) suggested that both the capacity and activity of photosynthesis were negatively affected by the treatment, indicating that PSII is impaired (Chen et al., 2016), which could be further proved by the increased $Y(N O)$ and decreased Qp. In FACHB-1563, Fv/Fm and Y(II) declined 

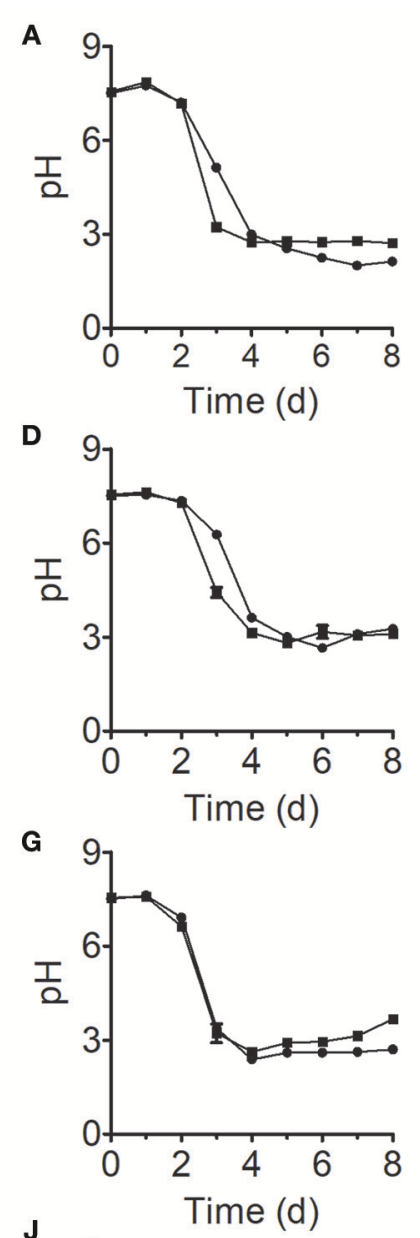

J

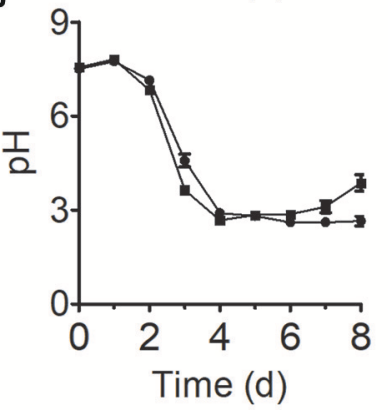

B

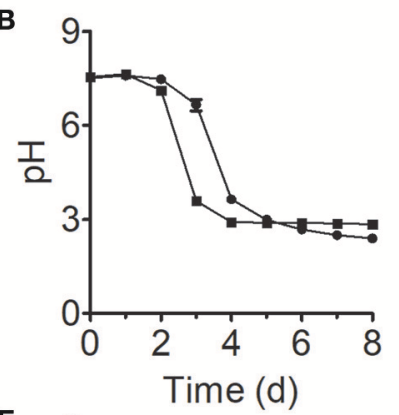

E

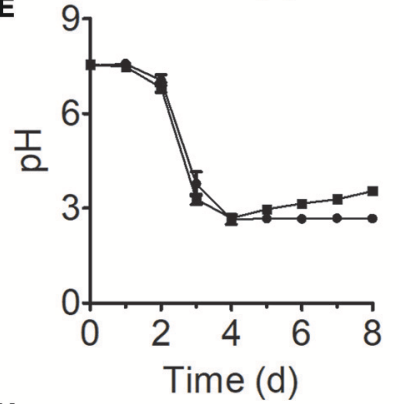

H

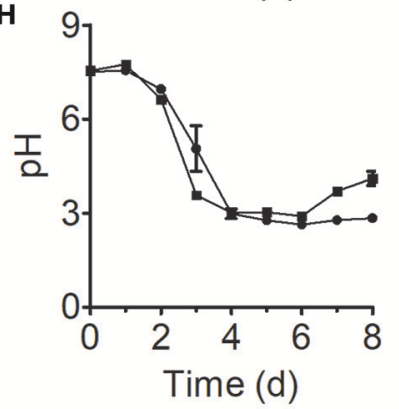

- $\mathrm{HC}$

- LC
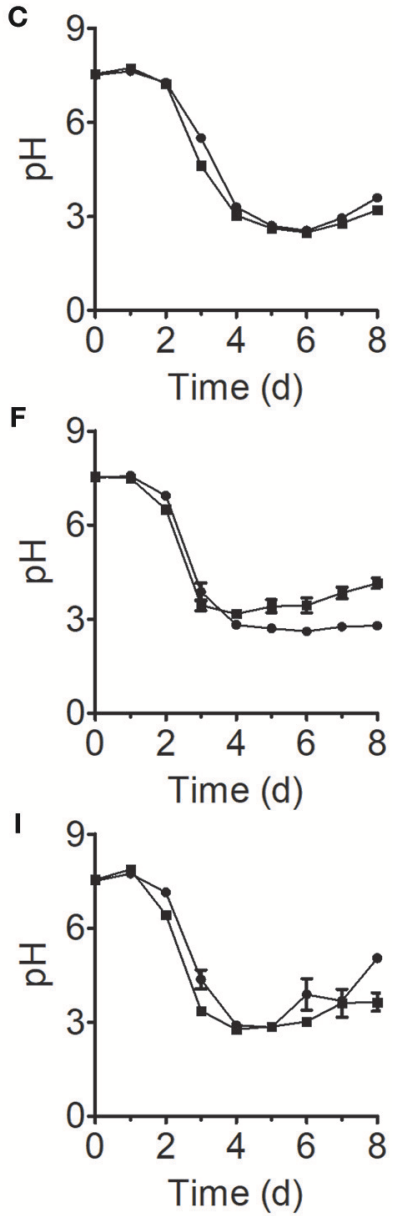

FIGURE 3 | pH changes in 10 Chlorella strains cultivated in HC (circles) and LC (squares) medium. (A-J) Represent Chlorella strain FACHB-1, FACHB-1216, FACHB-1535, FACHB-1563, W1, W2, W3, W4, W5, and W6, respectively.

by $\sim 40$ and $50 \%$, respectively, after a 5 -h cultivation under $\mathrm{HC}$ conditions but dropped to 0 in FACHB-1216 (Figures 7A,B). In contrast to the slight increase in $\mathrm{Y}(\mathrm{NO})$ in FACHB1563, this value increased nearly four-fold in FACHB-1216 (Figure 7C). The Qp value of FACHB-1563 was stable, whereas it dropped to 0 by the fourth hour of treatment in FACHB-1216 (Figure 7D).

To investigate whether the damage of PSII in response to ammonium nitrogen treatment is associated with changes in PSII protein content, we examined the effects of ammonium nitrogen on several major PSII proteins by immunoblot analysis (Figure 8). D1 protein content decreased in both FACHB-1216 and FACHB-1563 with increasing culture time. In FACHB-1216, CP43 protein levels showed the same tendency as D1, but in FACHB-1563, CP43 protein levels were stable, revealing more serious damage to PSII in FACHB1216. Together, these results suggested that the toxicity of ammonium nitrogen to Chlorella is due to its damaging effects on PSII, especially in the highly sensitive strain, FACHB1216. 


\section{OEC Is the Primary Site of Damage by Ammonium Nitrogen}

To explore more details of the effects of ammonium nitrogen on PSII function in Chlorella, fast fluorescence kinetics, the OJIP curves for FACHB-1216 and FACHB-1563 were obtained and various parameters were calculated accordingly (Figure 9). As shown in Figure 9A, the curves of both FACHB-1216 and FACHB-1563 were elevated in the O-J segment within the first hour of $\mathrm{HC}$ treatment, and the

TABLE 1 | $E_{50}$ of 10 Chlorella strains after $2 \mathrm{~h}$ of ammonium nitrogen treatment.

\begin{tabular}{|c|c|c|c|}
\hline \multirow{2}{*}{$\begin{array}{l}\text { Chlorella } \\
\text { strain }\end{array}$} & \multicolumn{3}{|c|}{$95 \%$ confidence limit for concentration } \\
\hline & Estimate $\left(\mathrm{g} \mathrm{L}^{-1}\right)$ & Lower limit $\left(\mathrm{g} \mathrm{L}^{-1}\right)$ & Upper limit $\left(g \mathrm{~L}^{-1}\right)$ \\
\hline FACHB-1 & $0.827^{A}$ & 0.646 & 1.024 \\
\hline FACHB-1216 & $0.404^{\mathrm{B}}$ & 0.371 & 0.437 \\
\hline FACHB-1535 & $1.665^{\mathrm{C}}$ & 1.570 & 1.765 \\
\hline FACHB-1563 & $1.679^{\mathrm{C}}$ & 1.499 & 1.885 \\
\hline W1 & $0.906^{A}$ & 0.790 & 1.023 \\
\hline W2 & $1.193^{\mathrm{A}}$ & 1.093 & 1.290 \\
\hline W3 & $1.159^{\mathrm{A}}$ & 0.999 & 1.322 \\
\hline W4 & $1.185^{\mathrm{A}}$ & 1.078 & 1.290 \\
\hline W5 & $1.135^{\mathrm{A}}$ & 0.889 & 1.401 \\
\hline W6 & $0.930^{\mathrm{A}}$ & 0.720 & 1.154 \\
\hline
\end{tabular}

Significance was determined using a one-way ANOVA. Different superscript letters (A, B, and $C)$ indicate significant differences among strains $(P<0.05)$.
$\mathrm{K}$ phase appeared, indicating that the OEC of PSII was damaged. The O-J segment continued to rise in FACHB1216, but tended to be stable in FACHB-1563, which has high tolerance to ammonium nitrogen, after the first hour of treatment.

Among various JIP-test parameters, $\varphi$ Eo represents the efficiency of the electron transport chain; decreasing values reflect inhibited electron transport in PSII (Strasser et al., 2004; Pan et al., 2008). $\varphi$ Eo decreased in both FACHB-1216 and FACHB-1563 during the first hour of $\mathrm{HC}$ treatment, indicating that electron transfer was affected in both strains. The $\varphi$ Eo value of FACHB-1216 continued to decrease, dropping to almost 0 at $5 \mathrm{~h}$ of treatment, whereas no significant changes were detected in FACHB1563. These results indicate that electron transport was more severely inhibited in FACHB-1216 than in FACHB-1563 (Figure 9C).

Wk reflects the condition of the OEC, and increases with damaging OEC (Zhang et al., 2017). During the first hour of exposure to high ammonium nitrogen levels, Wk increased rapidly (by nearly 1.5-fold) in both FACHB-1216 and FACHB1563 , indicating initial damage to the OEC. Subsequently, the Wk value continued to increase (by two-fold) in FACHB-1216, but remained stable in FACHB-1563 (Figure 9D).

Mo is the initial slope of the OJIP curve, which represents the $\mathrm{Q}_{\mathrm{A}}$ reduction rate; whereas the $\Psi_{\mathrm{O}}$ value reflects the probability that captured excitons will transfer electrons to $\mathrm{Q}_{\mathrm{A}}^{-}$, the downstream electron acceptor in the electron transport chain (Zhang et al., 2016). Therefore, changes in Mo and $\Psi_{\mathrm{O}}$ reflect changes in electron transport from $\mathrm{Q}_{\mathrm{A}}^{-}$to $\mathrm{Q}_{\mathrm{B}}$. In

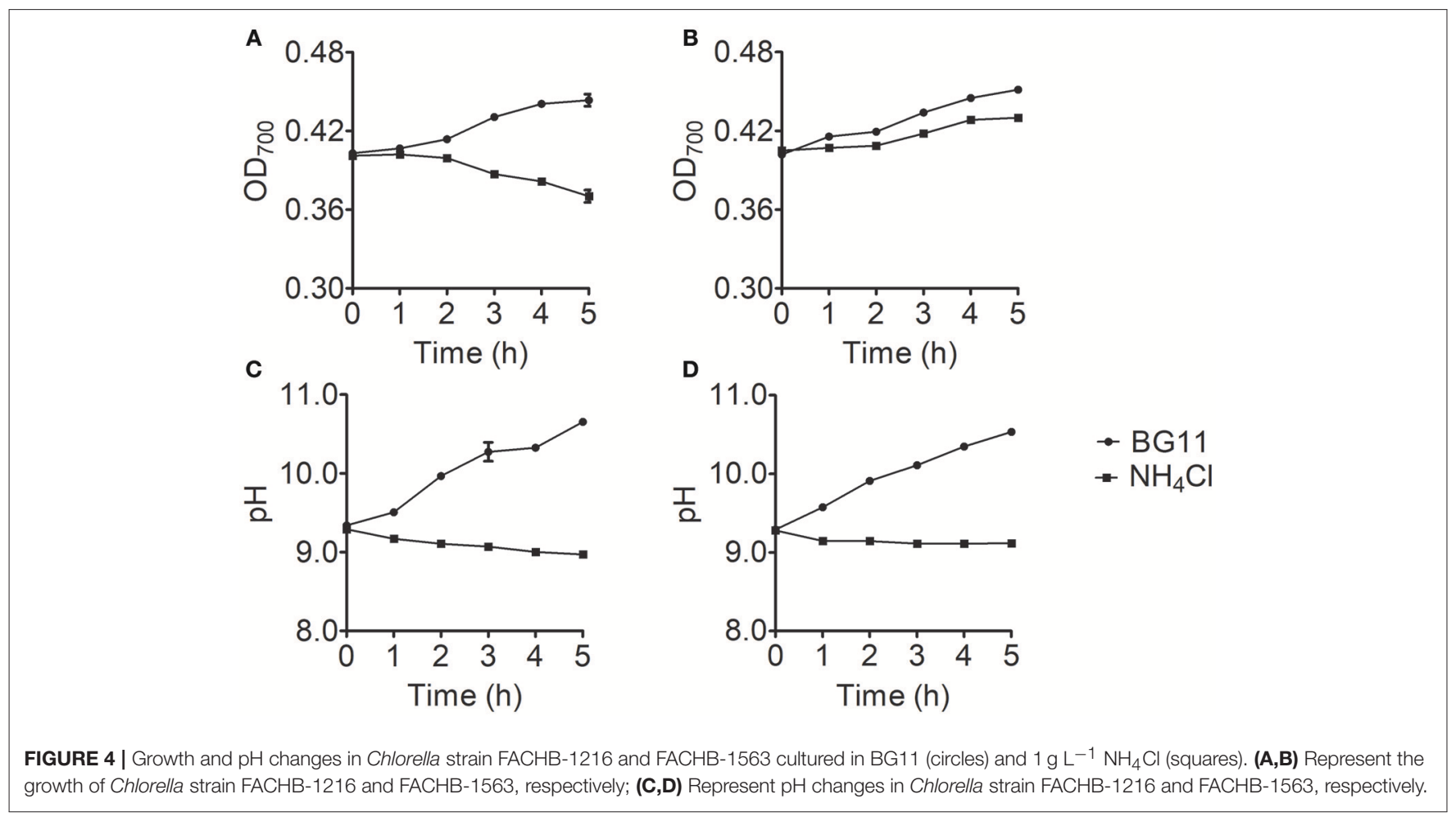





FIGURE 5 | Relative enzyme activity of GS and GOGAT in Chlorella strain FACHB-1216 and FACHB-1563 after incubation for $5 \mathrm{~h}$ in BG11 and $1 \mathrm{~g} \mathrm{~L}^{-1} \mathrm{NH}_{4} \mathrm{Cl}$. $(\mathbf{A}, \mathbf{B})$ Represent the enzymes GS and GOGAT, respectively. The control (BG11) values were set to 1 to facilitate comparison. The significance of the differences between the control (BG11) and other values was tested using a one-way ANOVA. ${ }^{\star} P<0.05 ;{ }^{\star \star} P<0.01$.
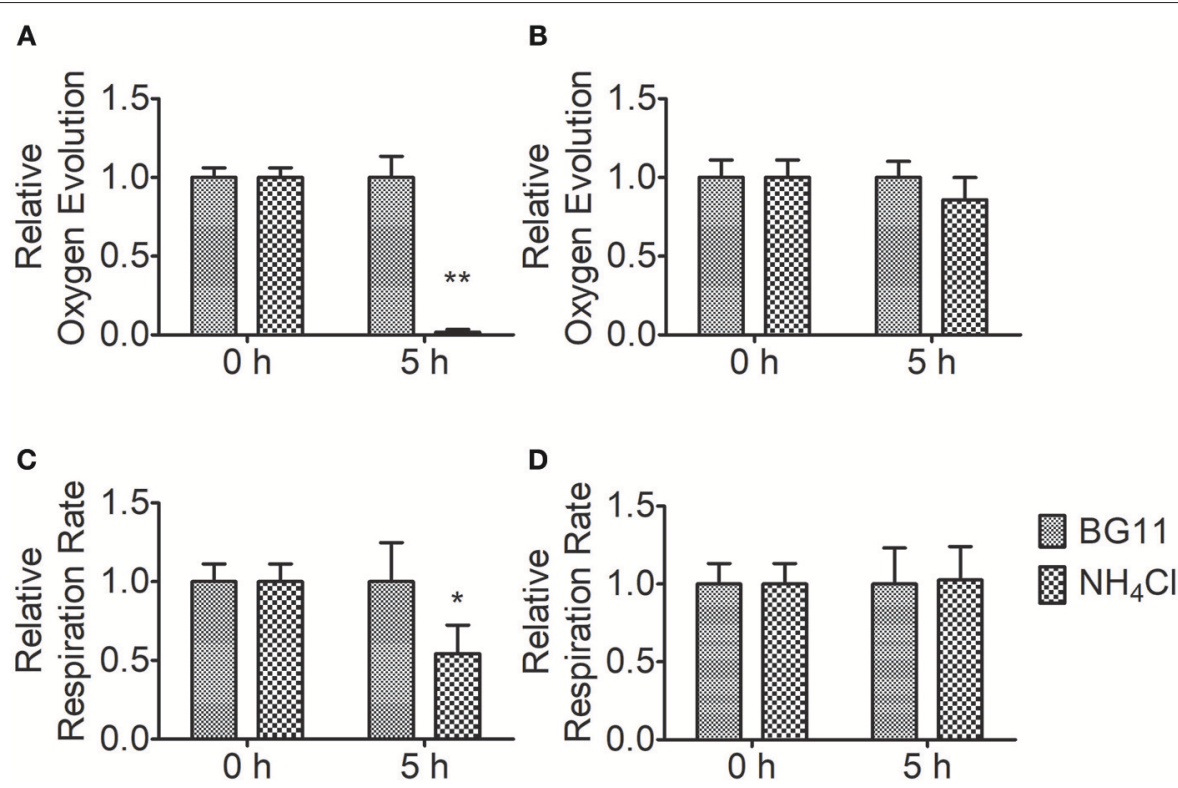

FIGURE 6 | Relative photosynthetic oxygen evolution rate and respiratory oxygen consumption of Chlorella strains FACHB-1216 and FACHB-1563 cultured in BG11 and $1 \mathrm{~g} \mathrm{~L}^{-1} \mathrm{NH}_{4} \mathrm{Cl}$. (A,B) Represent the photosynthetic oxygen evolution of Chlorella strain FACHB-1216 and FACHB-1563, respectively; (C,D) Represent the respiratory oxygen consumption of Chlorella strain FACHB-1216 and FACHB-1563, respectively. The significance of the differences between the same sample at $0 \mathrm{~h}$ and $5 \mathrm{~h}$ was tested using a one-way ANOVA. ${ }^{\star} P<0.05$; ${ }^{\star \star} P<0.01$.

FACHB-1563, Mo and $\Psi_{0}$ did not noticeably change throughout the culture period. By contrast, these values were stable in FACHB-1216 during the first hour of HC treatment, but subsequently Mo increased by nearly $300 \%$ and $\Psi_{0}$ decreased by $\sim 30 \%$ (Figures $9 E, F$ ). These results indicate that electron transport from $\mathrm{Q}_{\mathrm{A}}^{-}$to $\mathrm{Q}_{\mathrm{B}}$ was inhibited in FACHB-1216 after the first hour of treatment with high levels of ammonium nitrogen.

In summary, ammonium nitrogen inhibited the electron transport chain efficiency of PSII. OEC was the primary target site and was rapidly damaged. Electron transport from $\mathrm{Q}_{\mathrm{A}}^{-}$to $\mathrm{Q}_{\mathrm{B}}$ was also inhibited by ammonium nitrogen, but this inhibition followed damage to the OEC and could be alleviated in algae with high tolerance to ammonium nitrogen.

\section{DISCUSSION}

Ammonium nitrogen is one of the most energy-efficient nitrogen sources for algal metabolism (Ruan and Giordano, 2017). However, high concentrations of ammonium nitrogen are toxic and can inhibit algal growth (Gutierrez et al., 2016), which could be due to the effects of $\mathrm{NH}_{3}$ and $\mathrm{NH}_{4}^{+} \cdot \mathrm{NH}_{3}$ is thought to be the most toxic form of ammonium nitrogen due it its lack of charge and its lipid solubility, allowing it to readily diffuse across the cell membrane (Collos and Harrison, 2014). $\mathrm{NH}_{4}^{+}$is far less toxic than $\mathrm{NH}_{3}$ (Azov and Goldman, 1982; Kallqvista and Svenson, 2003), as the transport of $\mathrm{NH}_{4}^{+}$from extracellular regions requires the participation of transporters. When $\mathrm{CO}_{2}$ is used as carbon source, the $\mathrm{pH}$ of the medium is depended 

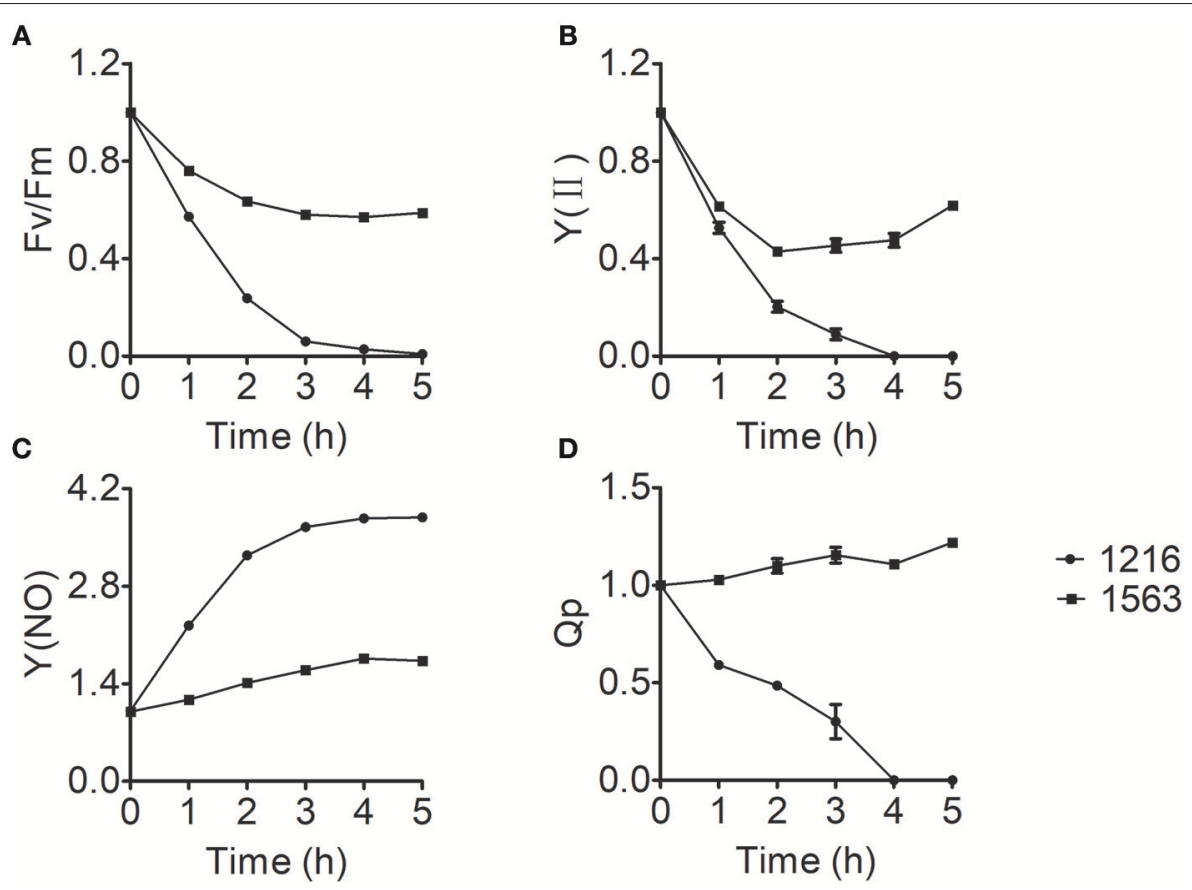

FIGURE 7 | (A-D) Relative fluorescence parameters of Chlorella strain FACHB-1216 (circles) and FACHB-1563 (squares) cultured in BG11 and $1 \mathrm{~g} \mathrm{~L}^{-1} \mathrm{NH}_{4} \mathrm{Cl}$. The control $(0 \mathrm{~h})$ values were set to 1.
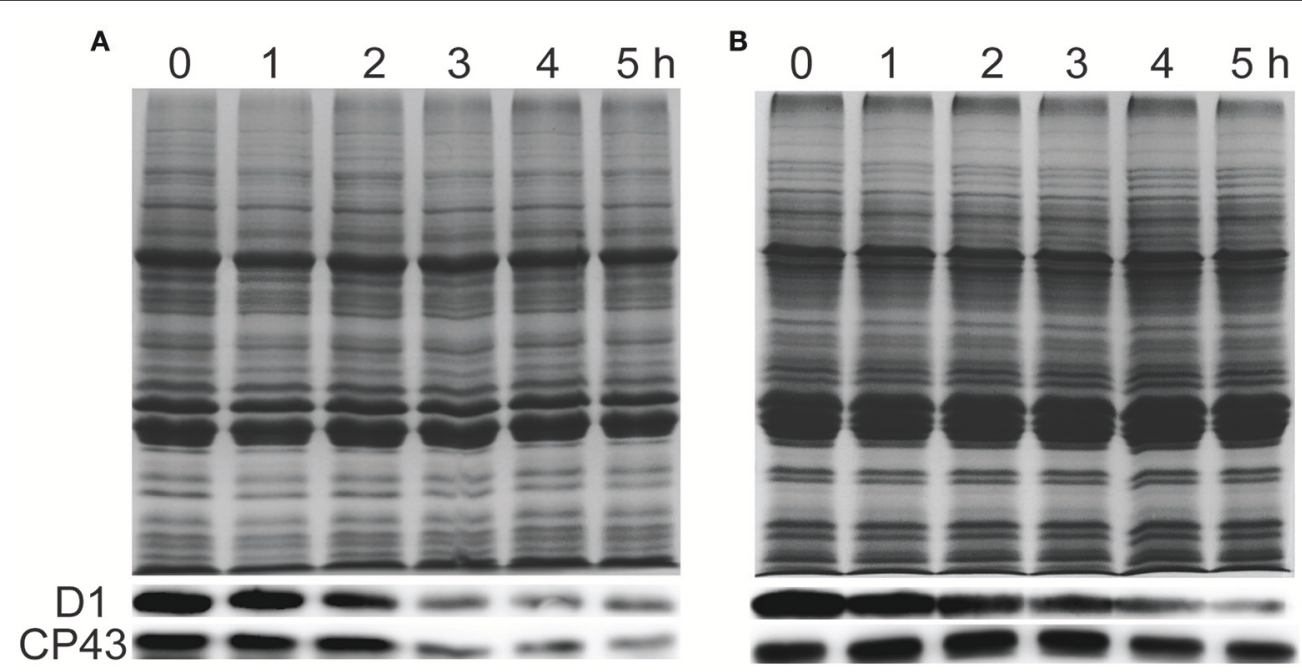

FIGURE 8 | Immunoblot analysis was performed using an antibody specific to D1 and CP43 (lower panels). Equal loading was confirmed by Coomassie brilliant blue staining (upper panels). (A,B) Represent Chlorella strain FACHB-1216 and FACHB-1563, respectively.

on the $\mathrm{CO}_{2}$ assimilation rate. If the dissolution rate of $\mathrm{CO}_{2}$ is greater than that of assimilation, the continuous $\mathrm{CO}_{2}$ dissolution results in the accumulation of $\mathrm{HCO}_{3}^{-}$and $\mathrm{H}^{+}$, so excessive $\mathrm{CO}_{2}$ penetration will lead to acidification of the medium. On the contrary, if the assimilation rate is high, the amount of $\mathrm{CO}_{2}$ assimilation is not enough to satisfy the need of carbon sources for cell and $\mathrm{HCO}_{3}^{-}$would be assimilated as carbon source by the cell, which makes the $\mathrm{K}^{+} / \mathrm{Na}^{+}$accumulated in the medium, causing alkalization of the medium. In this study, the cells were cultured in BG11 with shaking but not aerating, and $\mathrm{NaHCO}_{3}$ and $\mathrm{NaNO}_{3}$ were the main carbon and nitrogen source. The continuous consumption of $\mathrm{NO}_{3}^{-}$and $\mathrm{HCO}_{3}^{-}$could lead to $\mathrm{Na}^{+}$accumulation, both of which cause medium alkalization (Figure 4). When ammonium nitrogen was used as nitrogen source, the assimilation of $\mathrm{NH}_{4}^{+}$does acidify the medium, and the assimilation of $\mathrm{HCO}_{3}^{-}$does alkalinize it. However, $\mathrm{OH}^{-}$ 



FIGURE 9 | Relative variable fluorescence and JIP-test parameters of Chlorella FACHB-1216 and FACHB-1563 cultured in BG11 and $1 \mathrm{~g} \mathrm{~L}^{-1} \mathrm{NH}_{4} \mathrm{Cl}$. (A,B) Represent Chlorella strain FACHB-1216 and FACHB-1563, respectively. (C-F) Represent Mo, $\Psi \circ$, $\phi E \mathrm{E}$, and Wk, respectively. The control (0 h) values were set to 1.

produced during the $\mathrm{HCO}_{3}^{-}$assimilation in the cell could not neutralize the excess $\mathrm{H}^{+}$produced by $\mathrm{NH}_{4}^{+}$assimilation, which led to medium acidification (Figure 4). Some studies reported that with gaseous $\mathrm{CO}_{2}$ as carbon source, excess $\mathrm{H}^{+}$or $\mathrm{OH}^{-}$ produced during the assimilation in the cell was mainly decided by nitrogen source and one $\mathrm{NH}_{4}^{+}$assimilated by cell would produce at least one $\mathrm{H}^{+}$in plant cell cytoplasm (Raven and Smith, 1976; Raven, 1986; Andrews et al., 2013). Excess $\mathrm{H}^{+}$ should be neutralized to maintain cytoplasmic $\mathrm{pH}$, and net $\mathrm{H}^{+}$ efflux from cell was often greater than its $\mathrm{pH}$-regulation capacity (Raven, 1986), acidifying the surrounded environment. Usually, it is known that ammonium nitrogen can result in uncoupling of electron transfer and proton pumping, consequently, cause an acidification in cells of Chlorella. Thus the transformation of $\mathrm{NH}_{4}^{+}$is restricted in chloroplasts and further regulated by its assimilation rate (Flores and Herrero, 2015). Therefore, the assimilation rate of ammonium nitrogen determines the tolerance of algae strain. Normally, the ratio of $\mathrm{NH}_{4}^{+}$to $\mathrm{NH}_{3}$ in the growth medium is mainly determined by $\mathrm{pH}$, with increasing $\mathrm{pH}$ levels leading to increased $\mathrm{NH}_{3}$ content (Collos and Harrison, 2014); thus, the form and toxicity of ammonium nitrogen present in the medium are associated with $\mathrm{pH}$ (Markou et al., 2014; Tan et al., 2016).

Here, we examined the tolerance of 10 Chlorella strains to ammonium nitrogen, which could be divided into three categories (Table 1): good tolerance (FACHB-1563 and FACHB1535), fair tolerance (FACHB-1, W1, W2, W3, W4, W5, and W6), and poor tolerance (FACHB-1216). The growth of these 10 Chlorella strains under $\mathrm{HC}$ culture conditions, in which $\mathrm{NH}_{4}^{+}$ is the dominant form of ammonium nitrogen, could roughly be divided into two modes (Figure 1): fast-slow growth mode, in which rapid growth in the early stage is followed by reduced growth in the middle and late stages (FACHB-1, 1535, 1563, W1, W2, W3, W4, W5, and W6) and slow growth mode, in 


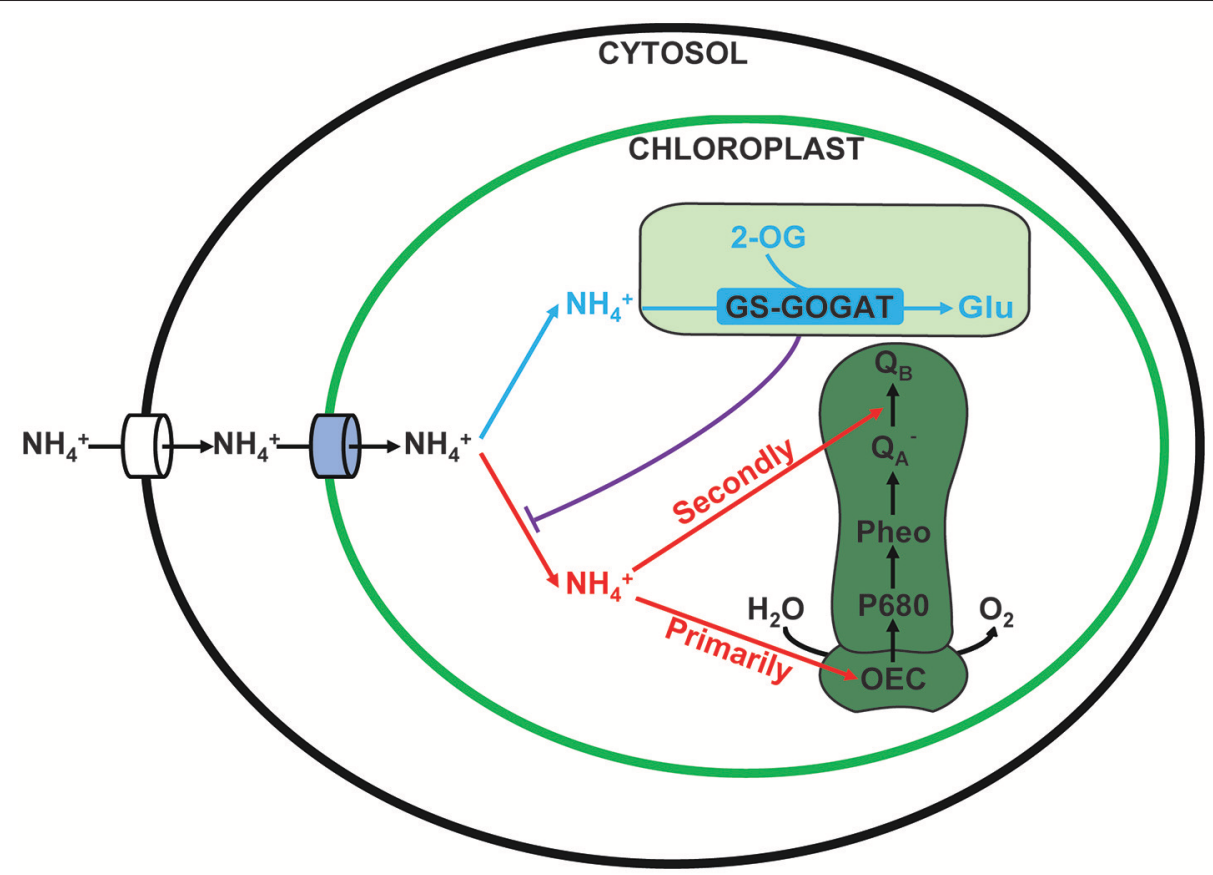

FIGURE 10 | Competition between assimilation and PSII damage by ammonium nitrogen in the chloroplast. When ammonium nitrogen was transported into the chloroplast, it could be taken as: 1. N source and being assimilated into nontoxic organic nitrogen by GS-GOGAT (in blue), and 2. hazardous material that being toxic to photosynthesis, which initially damaging the OEC and then blocking electron transport from $Q_{A}^{-}$to $Q_{B}$ (in red). The damaging effects on $P S I l$ are dependent on the assimilation rate, which is further up to the activities of the GS-GOGAT.

which inhibited growth occurs throughout the culture period (FACHB-1216). Algae with a fast-slow growth mode had fair or good tolerance to ammonium nitrogen and grew normally during the early stage of growth. However, as $\mathrm{NH}_{4}^{+}$became assimilated by the cell, the medium gradually became acidified (Figure 3), which indirectly inhibited the growth of the algae (Xin et al., 2010). FACHB-1216, the only alga with a slow growth mode, had poor tolerance to ammonium nitrogen. High levels of ammonium nitrogen had a direct effect on its cell growth, which was inhibited throughout the culture period. Therefore, high levels of ammonium nitrogen can directly affect the growth of algae with poor tolerance of this compound. By contrast, the growth of algae with high tolerance to ammonium nitrogen is not affected at the initial stage of growth, but the assimilation of $\mathrm{NH}_{4}^{+}$ by the algae leads to acidification of the medium, which indirectly inhibits algal growth.

Ammonium nitrogen toxicity may be universal, but the threshold at which symptoms of toxicity become manifested differs widely among algae. Collos and Harrison (2014) compared the effects of high ammonium nitrogen concentrations on the growth of six classes of microalgae, and found that Chlorophytes were significantly more tolerant to high ammonium nitrogen levels than were diatoms, prymnesiophytes, dinoflagellates, and raphidophytes. Within the same class of algae, different strains also have significantly different levels of tolerance to ammonium nitrogen. The sensitivity of five cyanobacterial strains to ammonium nitrogen toxicity is as follows: Ge-XianMi > Anabaena azotica FACHB $118>$ Microcystis aeruginosa
FACHB $905>$ M. aeruginosa FACHB $315>$ Synechococcus FACHB 805 (Dai et al., 2008). In this study, we assessed the tolerance of 10 Chlorella strains to ammonium nitrogen (Table 1), and found that the degree of tolerance is strain-specific, with FACHB-1563 and FACHB-1216, respectively, having the highest and lowest tolerance to ammonium nitrogen among the 10 Chlorella strains tested. The activity of GS-GOGAT display a marked difference (Figure 5) in the two strains with different tolerance to ammonium nitrogen. In the strain with high GSGOGAT activity, $\mathrm{NH}_{4}^{+}$can be effectively converted into organic nitrogen, thus avoiding the accumulation of $\mathrm{NH}_{4}^{+}$in cells and effectively reducing ammonia toxicity, which suggested that the ability to assimilate ammonium nitrogen determines the tolerance of Chlorella to ammonium nitrogen. Same conclusion has also been drew by Gumenyuk (2003), and he found that the green algae with higher tolerance to high ammonium have higher GS/GDH activities. Remove of toxic nitrogen promptly would improve the tolerance of cell to nitrogen (Collos and Harrison, 2014).

Numerous studies have focused on screening microalgae for high tolerance to harmful substances to identify strains that can be used for the bioremediation of wastewater. Monoraphidium spp. SDEC-17, which can endure high-ammoniacal nitrogen conditions ( $>170 \mathrm{mg} \mathrm{L}^{-1}$ ), represents a promising candidate for algal biomass production and chemical energy recovery from complex wastewater (Jiang et al., 2016). However, besides high tolerance to ammonium nitrogen, both high nitrogen utilization efficiency and high growth rate are also deciding factors in 
algal bioremediation of ammonium nitrogen from wastewater. Paskuliakova et al. (2016) used four chlorophyte strains to reduce the level of ammonium nitrogen in landfill leachate and a reduction rate of $3.77 \mathrm{mg} \mathrm{L}^{-1} \mathrm{~d}^{-1}$ of ammonium nitrogen was detected in $\sim 100 \mathrm{mg} \mathrm{L}^{-1}$ ammonium nitrogen. In the study of Tam and Wong (1996), Chlorella vulgaris was used to remove ammonium nitrogen, and a $3.61 \mathrm{mg} \mathrm{L}^{-1} \mathrm{~d}^{-1}$ removal efficiency was acquired in $\sim 125 \mathrm{mg} \mathrm{L}^{-1} \mathrm{NH}_{4}^{+}-\mathrm{N}$. In this study, FACHB1563 , cultured in $\mathrm{HC}$ condition $\left(500 \mathrm{mg} \mathrm{L}^{-1}\right)$, showed the same growth rate with the control group in the first 3 days (Figure 1), and an ammonium nitrogen assimilation rate of $4.27 \mathrm{mg} \mathrm{L}^{-1}$ $\mathrm{d}^{-1}$ was observed with traces initial inoculation $\left(\mathrm{OD}_{700} 0.1\right)$ (Figure 2). Therefore, FACHB-1563 exhibits high tolerance to ammonium nitrogen (Table 1), with high removal rate (Figure 2) and high growth rate (Figure 1), making it an excellent candidate for use in removing ammonium nitrogen from wastewater.

Ammonium nitrogen is toxic to algae due to its damaging effects on photosynthesis (Azov and Goldman, 1982; Drath et al., 2008). Ammonium nitrogen directly induces photodamage to PSII rather than affecting the repair of photodamaged PSII (Dai et al., 2014). The toxic effects of ammonium nitrogen on photosynthesis appear to be complex, as this compound affects not only PSII, but also PSI, the electron transport chain, and the OEC (Markou et al., 2016). The OEC is the main site of damage, as $\mathrm{NH}_{3}$ is a structural analog of the substrate $\mathrm{H}_{2} \mathrm{O}$ and an inhibitor of the water oxidation reaction in PSII, and is thus able to replace substrate water molecules in the OEC in PSII (Hou et al., 2011; Tsuno et al., 2011). In this study, we explored the effect of ammonium nitrogen on PSII in algae based on an analysis of chlorophyll fluorescence, photosynthetic oxygen evolution, and photosynthetic protein detection (Figures 6-8).

\section{REFERENCES}

Alves, L. S., Torres Junior, C. V., Fernandes, M. S., Marques dos Santos, A., and Regina de Souza, S. (2016). Soluble fractions and kinetics parameters of nitrate and ammonium uptake in sunflower ("Neon" Hybrid). Rev. CiÊncia Agron. 47, 13-21. doi: 10.5935/1806-6690.20160002

Andrews, M., Raven, J. A., and Lea, P. J. (2013). Do plants need nitrate? The mechanisms by which nitrogen form affects plants. Ann. Appl. Biol. 163, 174-199. doi: 10.1111/aab.12045

Azov, Y., and Goldman, J. C. (1982). Free ammonia inhibition of algal photosynthesis in intensive cultures. Appl. Environ. Microbiol. 43, 735-739.

Chen, H., Zheng, Y. L., Zhan, J., He, C. L., and Wang, Q. (2017). Comparative metabolic profiling of the lipid-producing green microalga Chlorella reveals that nitrogen and carbon metabolic pathways contribute to lipid metabolism. Biotechnol. Biofuels 10:153. doi: 10.1186/s13068-017-0839-4

Chen, W. X., Zhang, S. S., Rong, J. F., Li, X., Chen, H., He, C. L., et al. (2016). Effective biological denox of industrial flue gas by the mixotrophic cultivation of an oil-producing green alga Chlorella sp c2. Environ. Sci. Technol. 50, 1620-1627. doi: 10.1021/acs.est.5b04696

Collos, Y., and Harrison, P. J. (2014). Acclimation and toxicity of high ammonium concentrations to unicellular algae. Mar. Pollut. Bull. 80, 8-23. doi: 10.1016/j.marpolbul.2014.01.006

Costa, J. A. V., Cozza, K. L., Oliveira, L., and Magagnin, G. (2001). Different nitrogen sources and growth responses of Spirulina platensis in microenvironments. World J. Microbiol. Biotechnol. 17, 439-442. doi: 10.1023/A:1011925022941
All of these parameters showed that PSII was negatively affected by ammonium nitrogen. Further fast kinetics OJIP analysis (Figure 9) revealed that the OEC was the first site damaged by ammonium nitrogen, followed by the electron transport from $Q_{A}^{-}$ to $\mathrm{Q}_{\mathrm{B}}$.

Based on the current study, a working model of ammonium nitrogen competition between $\mathrm{N}$ assimilation and PSII damage was proposed (Figure 10): when transported into the chloroplast, $\mathrm{NH}_{4}^{+}$can serve as both $\mathrm{N}$ source and hazardous material, thus could either be assimilated into non-toxic organic nitrogen (LGlu) by GS-GOGAT, or being toxic to photosynthesis, which initially damaging the OEC and then blocking electron transport from $\mathrm{Q}_{\mathrm{A}}^{-}$to $\mathrm{Q}_{\mathrm{B}}$, and the GS-GOGAT catalyzed $\mathrm{NH}_{4}^{+}$assimilation is a relief to its damaging effects on PSII. For algae strains with high GS-GOGAT activities, the toxic $\mathrm{NH}_{4}^{+}$could be timely removed and transformed to avoid the immediate impact on PSII (Figures 6-9), thus showing high tolerance.

\section{AUTHOR CONTRIBUTIONS}

JW and QW designed the study. JW, WZ, HC, JZ, CH, and QW collected, analyzed, and interpreted the data. JW, HC, and QW wrote the manuscript.

\section{ACKNOWLEDGMENTS}

This work was supported jointly by the National Natural Science Foundation of China (31870041, 31770128, 31700107), Hubei Provincial Natural Science Foundation of China (2017CFA021), the State Key Laboratory of Freshwater Ecology and Biotechnology (2016FB11).

Cruz, H., Luckman, P., Seviour, T., Verstraete, W., Laycock, B., and Pikaar, I. (2018). Rapid removal of ammonium from domestic wastewater using polymer hydrogels. Sci. Rep. 8:2912. doi: 10.1038/s41598-018-21204-4

Dai, G., Deblois, C. P., Liu, S., Juneau, P., and Qiu, B. (2008). Differential sensitivity of five cyanobacterial strains to ammonium toxicity and its inhibitory mechanism on the photosynthesis of rice-field cyanobacterium Ge-Xian-Mi (Nostoc). Aquat. Toxicol. 89, 113-121. doi: 10.1016/j.aquatox.2008.06.007

Dai, G. Z., Qiu, B. S., and Forchhammer, K. (2014). Ammonium tolerance in the cyanobacterium Synechocystis sp. strain PCC 6803 and the role of the psbA multigene family. Plant Cell Environ. 37, 840-851. doi: 10.1111/pce.12202

Daniel-Vedele, F., Filleur, S., and Caboche, M. (1998). Nitrate transport: a key step in nitrate assimilation. Curr. Opin. Plant Biol. 1, 235-239. doi: 10.1016/S1369-5266(98)80110-6

Drath, M., Kloft, N., Batschauer, A., Marin, K., Novak, J., and Forchhammer, K. (2008). Ammonia triggers photodamage of photosystem II in the cyanobacterium Synechocystis sp. strain PCC 6803. Plant Physiol. 147, 206-215. doi: 10.1104/pp.108.117218

Fernandez, E., and Galvan, A. (2007). Inorganic nitrogen assimilation in Chlamydomonas. J. Exp. Bot. 58, 2279-2287. doi: 10.1093/jxb/erm 106

Flores, E., and Herrero, A. (2015). Nitrogen assimilation and nitrogen control in cyanobacteria. Biochem. Soc. Trans. 33, 164-167. doi: 10.1042/BST0330164

Gumenyuk, G. B. (2003). Peculiarities of ammonium nitrogen assimilation in green and blue-green algae. Hydrobiol. J. 39, 102-108. doi: 10.1615/HydrobJ.v39.i6.110

Gutierrez, J., Kwan, T. A., Zimmerman, J. B., and Peccia, J. (2016). Ammonia inhibition in oleaginous microalgae. Algal Res. 19, 123-127. doi: 10.1016/j.algal.2016.07.016 
Hoekstra, J. A. (1991). Estimation of the LC50. A review. Environmetrics 2, 139-152. doi: 10.1002/env. 3770020203

Hou, L. H., Wu, C. M., Huang, H. H., and Chu, H. A. (2011). Effects of ammonia on the structure of the oxygen-evolving complex in photosystem II as revealed by light-induced FTIR difference spectroscopy. Biochemistry 50, 9248-9254. doi: 10.1021/bi200943q

Huang, H. M., Xiao, X. M., and Yan, B. (2009). Recycle use of magnesium ammonium phosphate to remove ammonium nitrogen from rare-earth wastewater. Water Sci. Technol. 59, 1093-1099. doi: 10.2166/wst.2009.086

Ihnken, S., Beardall, J., Kromkamp, J. C., Gómez Serrano, C., Torres, M. A., Masojídek, J., et al. (2014). Light acclimation and $\mathrm{pH}$ perturbations affect photosynthetic performance in Chlorella mass culture. Aquat. Biol. 22, 95-110. doi: 10.3354/ab00586

Jiang, L., Pei, H., Hu, W., Hou, Q., Han, F., and Nie, C. (2016). Biomass production and nutrient assimilation by a novel microalga, Monoraphidium spp. SDEC17, cultivated in a high-ammonia wastewater. Energy Convers. Manage. 123, 423-430. doi: 10.1016/j.enconman.2016.06.060

Kallqvista, T., and Svenson, A. (2003). Assessment of ammonia toxicity in tests with the microalga, Nephroselmis pyriformis, Chlorophyta. Water Res. 37, 477-484. doi: 10.1016/S0043-1354(02)00361-5

Körner, S., Das, S. K., Veenstra, S., and Vermaat, J. E. (2001). The effect of $\mathrm{pH}$ variation at the ammonium_ammonia equilibrium in wastewater and its toxicity to Lemna gibba. Aquat. Bot. 71, 71-78. doi: 10.1016/S0304-3770(01)00158-9

Krause, G. H. (1991). Chlorophyll fluorescence and photosynthesis: the basics. Annu. Rev. Plant Physiol. Plant Mol. Biol. 42, 313-349. doi: 10.1146/annurev.pp.42.060191.001525

Kronzucker, H. J., Schjoerring, J. K., Erner, Y., Kirk, G. J. D., Siddiqi, M. Y., and Glass, A. D. M. (1998). Dynamic interactions between root $\mathrm{NH}_{4}^{+}$influx and long-distance $\mathrm{N}$ translocation in rice: insights into feedback processes. Plant Cell Physiol. 39, 1287-1293. doi: 10.1093/oxfordjournals.pcp.a029332

Lanyon, L. E. (1995). Does nitrogen-cycle - changes in the spatial dynamics of nitrogen with industrial nitrogen-fixation. J. Prod. Agric. 8, 70-78. doi: 10.2134/jpa1995.0070

Li, G., Dong, G., Li, B., Li, Q., Kronzucker, H. J., and Shi, W. (2012). Isolation and characterization of a novel ammonium overly sensitive mutant, amos 2 , in Arabidopsis thaliana. Planta 235, 239-252. doi: 10.1007/s00425-011-1504-y

Li, T. P., Xu, G., Rong, J. F., Chen, H., He, C. L., Giordano, M., et al. (2016). The acclimation of Chlorella to high-level nitrite for potential application in biological NOx removal from industrial flue gases. J. Plant Physiol. 195, 73-79. doi: 10.1016/j.jplph.2016.03.006

Lu, S. M., Liao, M. J., Xie, C. X., He, X. G., Li, D. P., Liu, Q. S., et al. (2015). Removing ammonium from aquaculture ponds using suspended biocarrier-immobilized ammonia-oxidizing microorganisms. Ann. Microbiol. 65, 2041-2046. doi: 10.1007/s13213-015-1042-0

Markou, G., Depraetere, O., and Muylaert, K. (2016). Effect of ammonia on the photosynthetic activity of Arthrospira and Chlorella : a study on chlorophyll fluorescence and electron transport. Algal Res. 16, 449-457. doi: 10.1016/j.algal.2016.03.039

Markou, G., Vandamme, D., and Muylaert, K. (2014). Ammonia inhibition on Arthrospira platensis in relation to the initial biomass density and $\mathrm{pH}$. Bioresour. Technol. 166, 259-265. doi: 10.1016/j.biortech.2014.05.040

Martin-Figueroa, E., Navarro, F., and Florencio, F. J. (2000). The GS-GOGAT pathway is not operative in the heterocysts. Cloning and expression of glsF gene from the cyanobacterium Anabaena sp PCC 7120. FEBS Lett. 476, 282-286. doi: 10.1016/S0014-5793(00)01722-1

Monier, A., Edgar, R. E., and Lovejoy, C. (2015). Diversity of nitrogen assimilation pathways among microbial photosynthetic eukaryotes. J. Phycol. 51, 490-506. doi: $10.1111 /$ jpy. 12292

Nishibayashi, Y., Saito, M., Uemura, S., Takekuma, S., Takekuma, H., and Yoshida, Z. (2004). Buckminsterfullerenes - A non-metal system for nitrogen fixation. Nature 428, 279-280. doi: 10.1038/428279b

Olivares, J., Bedmar, E. J., and Sanjuan, J. (2013). Biological nitrogen fixation in the context of global change. Mol. Plant-Microbe Interact. 26, 486-494. doi: 10.1094/MPMI-12-12-0293-CR

Pan, X., Deng, C., Zhang, D., Wang, J., Mu, G., and Chen, Y. (2008). Toxic effects of amoxicillin on the photosystem II of Synechocystis sp. characterized by a variety of in vivo chlorophyll fluorescence tests. Aquat. Toxicol. 89, 207-213. doi: 10.1016/j.aquatox.2008.06.018
Paskuliakova, A., Tonry, S., and Touzet, N. (2016). Phycoremediation of landfill leachate with chlorophytes: phosphate a limiting factor on ammonia nitrogen removal. Water Res. 99, 180-187. doi: 10.1016/j.watres.2016.04.029

Pearson, J., and Stewart, G. R. (1993). The deposition of atmospheric ammonia and its effects on plants. New Phytol. 125, 283-305. doi: 10.1111/j.1469-8137.1993.tb03882.x

Raven, J. A. (1986). Biochemical disposal of excess $\mathrm{H}^{+}$in growing plants? New Phytol. 104, 175-206. doi: 10.1111/j.1469-8137.1986.tb00644.x

Raven, J. A., and Smith, F. A. (1976). Nitrogen assimilation and transport in vascular land plants in relation to intracellular $\mathrm{pH}$ regulation. New Phytol. 76, 415-431. doi: 10.1111/j.1469-8137.1976.tb01477.x

Ruan, Z., and Giordano, M. (2017). The use of $\mathrm{NH}_{4}^{+}$rather than $\mathrm{NO}_{3}^{-}$affects cell stoichiometry, $\mathrm{C}$ allocation, photosynthesis and growth in the cyanobacterium Synechococcus sp. UTEX LB 2380, only when energy is limiting. Plant Cell Environ. 40, 227-236. doi: 10.1111/pce.12858

Speer, M., and Kaiser, W. M. (1994). Replacement of nitrate by ammonium as the nitrogen-source increases the salt sensitivity of pea-plants .2. Intercellular and intracellular solute compartmentation in leaflets. Plant Cell Environ. 17, 1223-1231. doi: 10.1111/j.1365-3040.1994.tb02020.x

Strasser, R. J., Tsimilli-Michael, M., and Srivastava, A. (2004). "Analysis of the chlorophyll a fluorescence transient," in Chlorophyll a Fluorescence: A Signature of Photosynthesis, eds G. C. Papageorgiou and Govindjee (Dordrecht: Springer Netherlands), 321-362. doi: 10.1007/978-1-4020-3218-9 12

Tam, N. F. Y., and Wong, Y. S. (1996). Effect of ammonia concentrations on growth of Chlorella vulgaris and nitrogen removal from media. Bioresour. Technol. 57, 45-50. doi: 10.1016/0960-8524(96)00045-4

Tan, X. B., Zhang, Y. L., Yang, L. B., Chu, H. Q., and Guo, J. (2016). Outdoor cultures of Chlorella pyrenoidosa in the effluent of anaerobically digested activated sludge: the effects of $\mathrm{pH}$ and free ammonia. Bioresour. Technol. 200, 606-615. doi: 10.1016/j.biortech.2015.10.095

Tsuno, M., Suzuki, H., Kondo, T., Mino, H., and Noguchi, T. (2011). Interaction and inhibitory effect of ammonium cation in the oxygen evolving center of photosystem II. Biochemistry 50, 2506-2514. doi: 10.1021/bi101952g

Williams, T. G., and Colman, B. (1996). The effects of $\mathrm{pH}$ and dissolved inorganic carbon on external carbonic anhydrase activity in Chlorella saccharophila. Plant Cell Environ. 19, 485-489. doi: 10.1111/j.1365-3040.1996.tb00341.x

$\mathrm{Wu}$, C., Xiong, W., Dai, J., and Wu, Q. (2016). Kinetic flux profiling dissects nitrogen utilization pathways in the oleaginous green alga Chlorella protothecoides. J. Phycol. 52, 116-124. doi: 10.1111/jpy.12374

Xin, L., Hong-ying, H., Ke, G., and Jia, Y. (2010). Growth and nutrient removal properties of a freshwater microalga Scenedesmus sp. LX1 under different kinds of nitrogen sources. Ecol. Eng. 36, 379-381. doi: 10.1016/j.ecoleng.2009.11.003

Zhang, L., Su, F., Zhang, C., Gong, F., and Liu, J. (2017). Changes of photosynthetic behaviors and photoprotection during cell transformation and astaxanthin accumulation in Haematococcus pluvialis grown outdoors in tubular photobioreactors. Int. J. Mol. Sci. 18, 33. doi: 10.3390/ijms18010033

Zhang, X., Chen, H., Chen, W. X., Qiao, Y. Q., He, C. L., and Wang, Q. (2014). Evaluation of an oil-producing green alga Chlorella sp. C2 for biological DeNO(x) of industrial flue gases. Environ. Sci. Technol. 48, 10497-10504. doi: $10.1021 /$ es5013824

Zhang, X., Ma, F., Zhu, X., Zhu, J. Y., Rong, J. F., Zhan, J., et al. (2016). The acceptor side of photosystem II is the initial target of nitrite stress in Synechocystis sp. strain PCC 6803. Appl. Environ. Microbiol. 83:e2952-16. doi: 10.1128/AEM.02952-16

Zhang, Y. M., Chen, H., He, C. L., and Wang, Q. (2013). Nitrogen starvation induced oxidative stress in an oil-producing green alga Chlorella sorokiniana C3. PLOS ONE 8:e69225. doi: 10.1371/journal.pone.0069225

Conflict of Interest Statement: The authors declare that the research was conducted in the absence of any commercial or financial relationships that could be construed as a potential conflict of interest.

Copyright () 2019 Wang, Zhou, Chen, Zhan, He and Wang. This is an open-access article distributed under the terms of the Creative Commons Attribution License (CC $B Y)$. The use, distribution or reproduction in other forums is permitted, provided the original author(s) and the copyright owner(s) are credited and that the original publication in this journal is cited, in accordance with accepted academic practice. No use, distribution or reproduction is permitted which does not comply with these terms. 